\title{
A Feasibility Study of Wastewater Treatment Using Domestic Microalgae and Analysis of Biomass for Potential Applications
}

\author{
Jeong-Mi Do ${ }^{1,2}{ }^{\circledR}$, Seung-Woo Jo ${ }^{3}$, Il-Sup Kim ${ }^{4}{ }^{\oplus}, \mathrm{Ho} \mathrm{Na}^{1,2}{ }^{\text {, Jae Hak Lee }}{ }^{1}$, Han Soon Kim ${ }^{1}$ \\ and Ho-Sung Yoon 1,2,3,4,* \\ 1 Department of Biology, College of Natural Sciences, Kyungpook National University, Daegu 41566, Korea; \\ leciel631@naver.com (J.-M.D.); myrambo10@naver.com (H.N.); hakis@knu.ac.kr (J.H.L.); \\ kimhsu@knu.ac.kr (H.S.K.) \\ 2 School of Life Sciences, BK21 Plus KNU Creative BioResearch Group, Kyungpook National University, \\ Daegu 41566, Korea \\ 3 Department of Energy Science, Kyungpook National University, Daegu 41566, Korea; jsw8796@gmail.com \\ 4 Advanced Bio-resource Research Center, Kyungpook National University, Daegu 41566, Korea; \\ 92kis@hanmail.net \\ * Correspondence: hsy@knu.ac.kr; Tel.: +82-53-950-5348; Fax: +82-53-953-3066
}

Received: 25 July 2019; Accepted: 26 October 2019; Published: 1 November 2019

\begin{abstract}
Water scarcity and emerging demands for renewable energy have increased concerns about energy security and advanced wastewater treatment, and microalgae have emerged as promising candidates to solve these problems. This study assesses the feasibility of microalgal wastewater treatment, and the utilization of the resulting microalgal biomass, as a renewable energy source. We cultured four selected microalgal species in filtered wastewater collected from the municipal treatment facility in Daegu, Republic of Korea. We measured nutrient consumption, growth rate, and physicochemical properties during cultivation, then analyzed the biomass for biochemical composition, ultimate analysis, proximate analysis, and biodiesel and lubricant properties, to estimate its potential applications. Desmodesmus sp. KNUA024 emerged as the most promising strain, removing $99.10 \%$ of ammonia nitrogen, $91.31 \%$ of total nitrogen, and $95.67 \%$ of total phosphate. Its biomass had a calorific value of $19.5 \mathrm{MJ} \mathrm{kg}^{-1}$, similar to terrestrial plants. $\alpha$-linolenic acid was the most abundant polyunsaturated fatty acid (PUFA; 54.83\%). Due to its PUFA content, Desmodesmus sp. KNUA024 also had a high iodine value, indicating its potential for use as a bio-lubricant. Therefore, Desmodesmus sp. KNUA024 shows promise for wastewater treatment, energy, and industrial applications.
\end{abstract}

Keywords: microalgae; wastewater treatment; bioenergy; bio-lubricant; alternative feedstock

\section{Introduction}

Due to the extensive use of fossil fuels, the world has been confronted with a depletion of energy sources and concomitant environmental problems, such as greenhouse gas accumulation and pollutant contamination of water. Thus, many countries are researching biological sources of energy and contaminant removal to develop sustainable and environmentally friendly resources. From this research, microalgae have emerged as a candidate. They are among the oldest organisms, prosper in a wide range of habitats almost anywhere on Earth's water bodies, and, because they have higher photosynthetic efficiency than terrestrial plants, they can rapidly convert water, light, and captured carbon to various forms of bioenergy, such as biodiesel, bioethanol, lipids, and carotenoids [1]. Moreover, they do not compete with food crops for cultivable land, because they can be cultivated on non-arable land [2]. 
However, commercialization of microalgae has an inherent challenge: due to the relatively high costs of the manufacturing process, they have low economic feasibility. An assortment of research has been conducted to increase the cost-effectiveness of microalgae cultivation [3], and growing microalgae with wastewater is a potential solution to this problem, because it is inexpensive and contains nutrient sources [4]. Indeed, microalgae can treat various kind of wastewater, including those from municipal, porcine, and industrial sources [5-8]. These studies suggest the feasibility of wastewater treatment using microalgae, which can decrease nutrient cost and water demand while improving water quality by reducing nutrient levels, biochemical oxygen demand (BOD), chemical oxygen demand (COD), coliform bacteria [9], and heavy metals. Furthermore, integrated approaches to wastewater treatment are also examining extended applications, such as biofuel, for the microalgal biomass remaining after wastewater treatment.

Because microalgae vary in suitability for wastewater treatment and biofuel applications, the viability of microalgae-based production also hinges on the selection of microalgal strains. Although microalgae can grow rapidly under optimal conditions, some strains do not perform as expected in large-scale cultivation, because wastewater and natural climate conditions deviate from the temperature, light cycle, $\mathrm{pH}$, and/or predation conditions of which the microalga is tolerant [10]. A suitable commercial organism should have broad tolerance to wastewater conditions under seasonally variable local conditions.

The purpose of this study was to evaluate the feasibility of domestic, Korean microalgae for wastewater treatment under local weather conditions. Moreover, we assessed several aspects of the potential applications of treated microalgal biomass. We carried out artificial wastewater (AW) [11] screening, with 20 varieties of domestic microalgae, to select the fastest-growing candidates. We then chose two additional dominant strains from mass cultivation in Chilgok, Korea, for their fast growth and flexibility under various climate conditions, with the expectation that these traits will apply to wastewater treatment conditions. We treated primary settled municipal wastewater and measured the nutrient removal efficiency and biomass productivity of four selected microalgal strain. We then analyzed the accumulated biomass for applications such as bioenergy, biodiesel, high-value product, and bio-lubricant, to determine how wastewater treatment using microalgae might also yield a source of renewable energy or replace non-renewable industrial needs.

\section{Materials and Methods}

\subsection{Selecting Candidate Strains for Wastewater Treatment}

\subsubsection{Screening Candidate Microalgae Using AW with KNUA Strains}

Seed cultures for 20 KNUA strains (Figure S1) were grown in BG-11 medium [12] for two weeks. To select candidates for wastewater treatment, all strains were grown in AW agar medium to ensure survival [11]. Exponentially growing cultures were collected and centrifuged at $6000 \mathrm{rpm}$ for $5 \mathrm{~min}$. Cells were then washed twice with distilled water. Washed cells were serially diluted 10-fold. To determine microalgal viability in $\mathrm{AW}$ conditions, $10 \mu \mathrm{L}$ of diluted solution was spotted on $\mathrm{AW}$ agar media and incubated at $25^{\circ} \mathrm{C}$ for $2-3$ weeks.

\subsubsection{Dominant Microalgae in Mass Cultivation in Chilgok}

Microalgae mass cultivation research was performed in Chilgok-gun Agricultural Technology Center ( $36^{\circ} 02^{\prime} 18.91^{\prime \prime} \mathrm{N}, 128^{\circ} 22^{\prime} 57.71^{\prime \prime}$ E; Dongan-ri, Yakmok-myeon, Chilgok-gun, Gyeongsangbukdo, Korea). In a previous study, we analyzed the transition of dominant microalgae and their predators, and then compared their biomass productivity with two identical 270 ton open pond raceways (OPR) [13]. 


\subsection{Wastewater Collection and Characterization}

Approximately $16 \mathrm{~L}$ of primary settled wastewater was collected from the Seo-bu Municipal Wastewater Treatment Facility, Daegu, Republic of Korea, on 23 June 2016. We measured the temperature, $\mathrm{pH}$, salinity, conductivity, total dissolved solids (TDS), and turbidity using a $\mathrm{pH} /$ multimeter (X-matePro MX300, Mettler Toledo, Switzerland). Total solids (TS) were estimated by standard methods [14]. COD, total nitrogen $(\mathrm{TN})$, ammonia nitrogen concentration $\left(\mathrm{NH}_{3}-\mathrm{N}\right)$, nitrate concentration $\left(\mathrm{NO}_{3}-\mathrm{N}\right)$, and total phosphorus (TP) were measured by water analysis kit (Humas, Daejeon, Korea). Metal concentrations were determined using an inductively coupled plasma spectrometer (Optima 7300DV, PerkinElmer, Waltham, MA, USA). All samples were filtered through a 0.2- $\mu \mathrm{m}$ filter (Ministart, Sartorius Stedim Biotech, Göttingen, Germany) before analysis of $\mathrm{COD}, \mathrm{TN}, \mathrm{NH}_{3}-\mathrm{N}, \mathrm{NO}_{3}-\mathrm{N}$, $\mathrm{TP}$ and metal concentration.

\subsection{Measurement of Growth Rate}

\subsubsection{Growth Conditions}

The experiment was carried out at $25^{\circ} \mathrm{C}, 16 / 8 \mathrm{~h}$ light, $114 \mu \mathrm{mol} \mathrm{m}{ }^{-2} \mathrm{~s}^{-1}$, and $160 \mathrm{rpm}$. Strains were maintained in BG-11 medium until the stationary phase. Cells were then centrifuged at $4000 \mathrm{rpm}$ for $5 \mathrm{~min}$ and washed twice with distilled water. Pellets were suspended with filtered wastewater and inoculated $10 \%(v / v)$ into $1 \mathrm{~L}$ sterile flasks containing $500 \mathrm{~mL}$ of filtered primary settled wastewater. All experiments were conducted for 11 days to assess when the stationary phase occurred, as identified by the maximum TN removal rate.

\subsubsection{Measurement of Growth Rate and Biomass Productivity}

To assess the growth rate of each microalgal strain, optical density (OD) was measured at $680 \mathrm{~nm}$ with a spectrophotometer (Optimizer 2120 UV spectrophotometer, Mecasys, Daejeon, Korea), and cellular density was counted daily with a light microscope (ZEISS Axio Imager A2, Germany) at 200× magnification, using an improved Neubauer chamber (C-Chip, DHC-N01-5, iNCYTO, Cheonan-si, Korea). The maximum specific growth rate $(\mu)$ was calculated as: $\mu=\ln \left(\mathrm{N}_{2} / \mathrm{N}_{1}\right) /\left(\mathrm{t}_{2}\right.$ $-t_{1}$ ), where $N_{2}$ and $N_{1}$ indicate the cell density per unit volume at times $t_{2}$ and $t_{1}$ during the exponential growth phase [15]. $\mathrm{pH}$ was evaluated daily with a $\mathrm{pH}$ meter (Seven Easy, Mettler, Toledo, $\mathrm{OH}$, USA). Microalgal dry weight $\left(\mathrm{g} \mathrm{L}^{-1}\right)$ was measured using the American Public Health Association (APHA)-recommended method [14].

\subsection{Measurement of Nutrient and Metal Removal}

To calculate the efficiency of nutrient removal from the microalgal cultures, media were filtered by a $0.2-\mu \mathrm{m}$ syringe filter. TN, TP, ammonia $\left(\mathrm{NH}_{3}-\mathrm{N}\right)$, and nitrate $\left(\mathrm{NO}_{3}-\mathrm{N}\right)$ were measured by HS-TN-L (CA), HS-TP-L, HS-NH $\mathrm{N}_{3}(\mathrm{~N})-\mathrm{L}, \mathrm{HS}-\mathrm{NO}_{3}(\mathrm{~N})-\mathrm{CA}$, and HS-2300 plus (Humas, Korea), respectively, daily. The nutrient removal percentage was calculated using:

$$
\% \text { Nutrient removal }=\frac{(\text { Initial concentration }- \text { Final concentration })}{\text { Initial concentration }} \times 100
$$

where final concentration indicates the lowest concentration of each nutrient.

The concentration of metals was determined when cells reached the lowest TN concentration, by using inductively coupled plasma (ICP, Optima 7300DV, PerkinElmer, Waltham, MA, USA).

\subsection{Measurement of Physicochemical Properties}

Chlorophyll $a$, Chlorophyll $b$, and total carotenoids were measured when microalgae cultures reached stationary phase, at which point total nitrogen concentrations were at their lowest. Collected cells were washed twice with distilled water, then centrifuged at 13,000 rpm for $5 \mathrm{~min}$. Pellets were suspended in $2 \mathrm{~mL}$ of methanol. To extract chlorophyll and carotenoid contents, cells were disrupted 
with ultrasonicationn (550 Sonic Dismembrator, Fisher Scientific, Hampton, NH, USA), at a resonance of $40 \mathrm{~Hz}$, for $5 \mathrm{~min}$. After disruption, solutions were centrifuged at 13,000 rpm for $5 \mathrm{~min}$. The supernatant was read on the spectrophotometer at $470 \mathrm{~nm}, 653 \mathrm{~nm}$, and $666 \mathrm{~nm}$. Chlorophyll $a$, chlorophyll $b$, and total carotenoid concentrations were estimated from the equations below [16]:

$$
\begin{gathered}
\text { Chlorophyll } a\left(\mathrm{C}_{\mathrm{a}}\right)=15.65 \mathrm{~A}_{666}-7.34 \mathrm{~A}_{653} \\
\text { Chlorophyll } b\left(\mathrm{C}_{\mathrm{b}}\right)=27.05 \mathrm{~A}_{653}-11.2 \mathrm{~A}_{666} \text {, and } \\
\text { Total carotenoids }=\left(1000 \mathrm{~A}_{470}-2.86 \mathrm{C}_{\mathrm{a}}-129.2 \mathrm{C}_{\mathrm{b}}\right) / 221
\end{gathered}
$$

\subsection{Biochemical Composition of Biomass}

When cells reached stationary phase and TN concentration was lowest, the cells were harvested, freeze-dried, and pulverized using a mortar. The biomass was characterized as a homogeneous powder passed through a test sieve (Mesh width ASTM 230, $63 \mu \mathrm{m}$, Chunggye, Korea). All biochemical composition assessments used this biomass.

In order to determine total carbohydrate content, the biomass was acid-hydrolyzed. Fifty milligrams of biomass were placed into a glass tube, to which $2.5 \mathrm{~mL}$ of $2.5 \mathrm{~N} \mathrm{HCl}$ was added. The contents were then boiled in a water bath for $3 \mathrm{~h}$ and cooled to room temperature $\left(25^{\circ} \mathrm{C}\right)$. The sample was neutralized with dropwise addition of sodium carbonate until bubbles ceased; the sample tube was then filled with distilled water to a final concentration of $1 \mathrm{mg} \mathrm{mL}^{-1}$. The hydrolyzed sample was put into a glass tube with $50 \mu \mathrm{L}$ of $80 \%$ phenol $(w / v)$, at which point $5 \mathrm{~mL}$ of concentrated sulfuric acid was added, and the solution was allowed to stand for $10 \mathrm{~min}$ at room temperature $\left(25^{\circ} \mathrm{C}\right)$.

The carbon $(\mathrm{C})$, hydrogen $(\mathrm{H})$, nitrogen $(\mathrm{N})$, and sulfur $(\mathrm{S})$ contents were determined using Flash 2000 elemental analyzer (Thermo Fisher Scientific, Milan, Italy) with lyophilized biomass. Protein contents were calculated from the $\mathrm{N}$ content using the conversion factor $(\times 6.25)$ [17].

A sulfo-phospho-vanillin (SPV) colorimetric method was used to measure total lipid content [18]. Ten milligrams of biomass were suspended with $1 \mathrm{~mL}$ of distilled water, then dispensed into different concentrations, with a total volume of $100 \mu \mathrm{L}$. Then, $2 \mathrm{~mL}$ of concentrated (98\%) sulfuric acid was mixed with the sample and boiled in a water bath for $5 \mathrm{~min}$. After boiling, it was cooled on ice; after $5 \mathrm{~min}, 5 \mathrm{~mL}$ of phospho-vanillin (PV) reagent, a solution of $0.6 \%$ of vanillin, in $10 \%$ absolute ethanol mixed with phosphoric acid, was added. The mixture was shaken at $37^{\circ} \mathrm{C}$ for $15 \mathrm{~min}$ at $200 \mathrm{rpm}$, and the supernatant was read on a spectrophotometer (Optizen 2120UV spectrophotometer, Mecasys, Korea) at $530 \mathrm{~nm}$. Total lipid contents were calculated from the lipid standard curve and equations were based on canola oil.

\subsection{Proximate and Ultimate Analysis}

In a proximate analysis by TGA, moisture content is demonstrated by the mass lost before $100{ }^{\circ} \mathrm{C}$ under a $\mathrm{N}_{2}$ atmosphere, volatile matter refers to the mass lost between $100-900{ }^{\circ} \mathrm{C}$ under $\mathrm{N}_{2}$, as a result of thermal decomposition, and the remaining mass indicates fixed carbon and ash [19]. Platinum pans with $30 \mathrm{mg} \alpha$-alumina $\left(\alpha-\mathrm{Al}_{2} \mathrm{O}_{3}\right)$ powder (Shimadzu, Japan) were used as reference material. After the addition of nitrogen gas at $25 \mathrm{~mL} \mathrm{~min}^{-1}$, TGA was performed using $10 \mathrm{mg}$ of the biomass, at a heating rate of $10^{\circ} \mathrm{C} \mathrm{min}^{-1}$ over $50 \mathrm{~min}$ to $900{ }^{\circ} \mathrm{C}$. The calorific value (CV) was calculated using [20]:

$$
\mathrm{CV}\left(\mathrm{MJ} \mathrm{kg}^{-1}\right)=0.3278 \mathrm{C}+1.419 \mathrm{H}+0.09257 \mathrm{~S}-0.1379 \mathrm{O}+0.637
$$

where $\mathrm{C}, \mathrm{H}$, and $\mathrm{S}$ are provided by the elemental analysis and $\mathrm{O}$ from the proximate analysis.

Ultimate analysis was conducted with a Flash 2000 elemental analyzer (Thermo Fisher Scientific, Italy) to determine $\mathrm{C}, \mathrm{H}, \mathrm{N}$, and $\mathrm{S}$ contents. Proximate analysis was conducted by thermogravimetric analysis (TGA), with a DTG-60A thermal analyzer (Shimadzu, Kyoto, Japan), to determine the oxygen, moisture, volatile matter, fixed carbon, and ash contents. 


\subsection{Analysis of Fatty Acid Methyl-Ester (FAME) Contents}

In order to analyze the FAME content of microalgae, $30 \mathrm{mg}$ of lyophilized biomass were used according to the methods of Breuer [21]. A Vortex-Genie (Scientific Industries, Bohemia, NY, USA) and a sonicator (Branson-5210, Branson Inc., Danbury, CT, USA) were used to disrupt the cells and extract lipids. Lipid extracts were transesterified to FAME by dilution in $5 \%(v / v) \mathrm{H}_{2} \mathrm{SO}_{4}$ in methanol and heating to $70^{\circ} \mathrm{C}$ for $3 \mathrm{~h}$. FAME composition of the sample was analyzed by gas chromatography (GC) mass spectrometry (Agilent 7890A GC equipped with 5975C MSD; Agilent Technologies, Santa Clara, CA, USA), with a DB-FFAP column $(30 \mathrm{~m} \times 250 \mu \mathrm{m} \times 0.25 \mu \mathrm{m})$. The initial GC oven temperature of $50{ }^{\circ} \mathrm{C}$ was maintained for $1 \mathrm{~min}$, increased to $200{ }^{\circ} \mathrm{C}$ at a rate of $10^{\circ} \mathrm{C} \mathrm{min}-1$, held for $30 \mathrm{~min}$, then increased to $240{ }^{\circ} \mathrm{C}$ at a rate of $10^{\circ} \mathrm{C} \mathrm{min}^{-1}$ and held for $20 \mathrm{~min}$. The injection size was $1 \mu \mathrm{L}$ and the split injection port was set to achieve a 20:1 ratio. Helium was used as the carrier gas at a constant flow rate of $1 \mathrm{~mL} \mathrm{~min}{ }^{-1}$.

\subsection{Biodiesel Properties Based on FAME Profiles}

Biofuel properties, such as the degree of unsaturation (DU), long-chain saturated factor (LCSF), saponification value (SV), iodine value (IV), cetane number (CN), cold filter plug-going point (CFPP), kinematic viscosity of at $40^{\circ} \mathrm{C}(\mathrm{v})$, density at $20^{\circ} \mathrm{C}(\varrho)$, and oxidative stability, were calculated based on the fatty acid profiles, using the equations below, to evaluate biofuel properties as described by the protocols listed by EN14214 and ASTM6751 [22-25]:

$$
\begin{gathered}
\mathrm{SV}=\sum \frac{560 \times \mathrm{F}}{\mathrm{MW}}, \mathrm{IV}=\sum \frac{254 \times \mathrm{F} \times \mathrm{N}}{\mathrm{MW}}, \mathrm{CN}=\left(46.3+\frac{5458}{\mathrm{SV}}\right)-(0.225 \times \mathrm{IV}), \\
\mathrm{LCSF}=(0.1 \times \mathrm{C} 16)+(0.5 \times \mathrm{C} 18)+(1 \times \mathrm{C} 20)+(1.5 \times \mathrm{C} 22)+(2 \times \mathrm{C} 24), \\
\mathrm{CFPP}=(3.1417 \times \mathrm{LCSF})-(16.477), \\
\mathrm{DU}=\sum \mathrm{MUFA}+(2 \times \mathrm{PUFA}), \\
\ln (v)=\sum-12.503+2.496 \times \ln (\mathrm{MW})-0.178 \times \mathrm{N}, \\
\varrho=\sum 0.8463+\frac{4.9}{\mathrm{MW}}+0.0118 \times \mathrm{N}, \text { and } \\
\text { Oxidative stability }=\frac{117.9295}{X}+2.5905(0<100)
\end{gathered}
$$

where $\mathrm{F}$ is the percentage; $\mathrm{MW}$ is the molecular weight; $\mathrm{N}$ is the number of double bonds, and $\mathrm{X}$ is the content of linoleic and linolenic acid in each FAME value. These equations have been previously validated for biofuel quality estimation of microalgae [23].

\section{Results}

\subsection{Selecting Candidate Strains for Wastewater Treatment}

Viability assessments in AW medium (Figure S1) indicated that Asterarcys quadricellulare KNUA020 (Figure 1a) was the fastest-growing species, followed by Tetradesmus obliquus KNUA019 (Figure 1b).

In the OPR, Desmodesmus sp. KNUA024 (Figure 1c) and Pseudopediastrum sp. KNUA039 (Figure 1d) were dominant throughout the year. Both strains were isolated and maintained in an axenic culture in the laboratory for further study. 

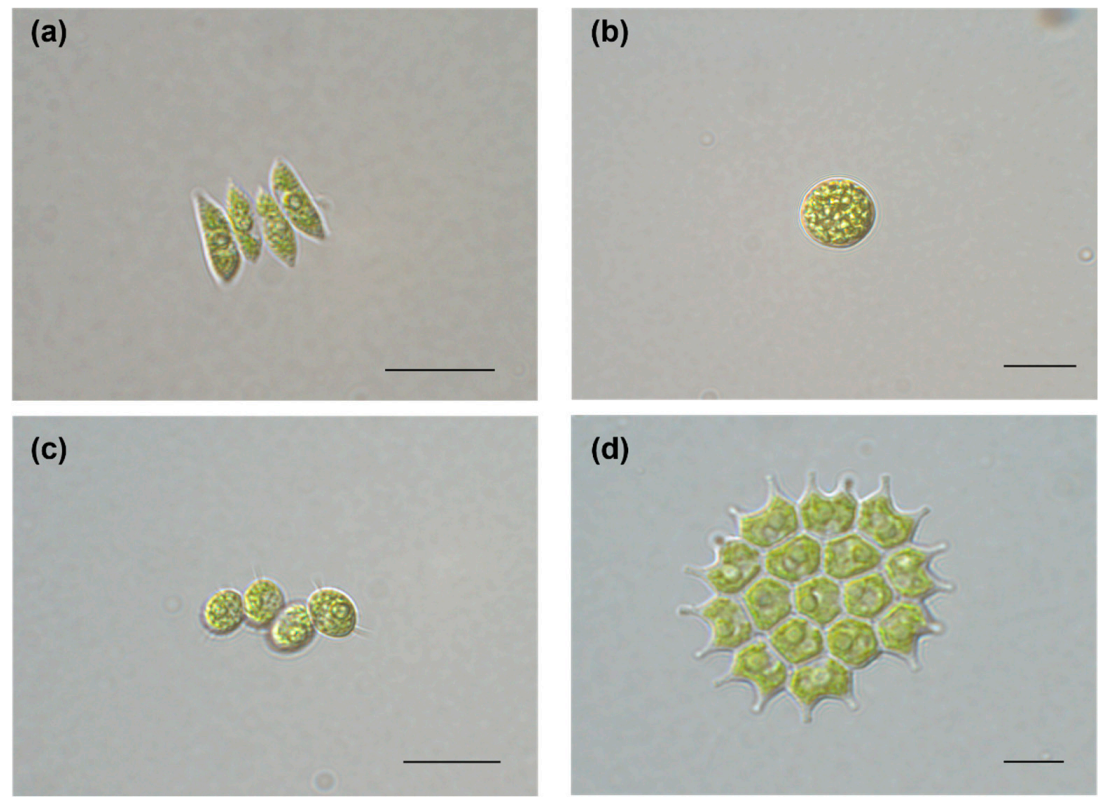

Figure 1. Light microscopy of each microalgal strain. (a) Tetradesmus obliquus KNUA019; (b) Asterarcys quadricellulare KNUA020; (c) Desmodesmus sp. KNUA024; (d) Pseudopediastrum sp. KNUA039. Scale bar: $10 \mu \mathrm{m}$.

\subsection{Wastewater Collection and Characterization}

We characterized the features of primary settled wastewater collected from the municipal wastewater treatment plant in Daegu, Republic of Korea (Table 1). The collected wastewater showed ambient water temperature and a neutral $\mathrm{pH}$. The primary nitrogen source was ammonia $\left(\mathrm{NH}_{3}-\mathrm{N}\right)$, and nitrate was undetectable (Table 1). We identified several minerals essential to microalgal growth and reproduction, including iron, magnesium, and sulfur (Table 1). Sodium and iron were the most and least abundant elements, respectively.

Table 1. General characteristics of primary settled wastewater from Seo-bu Municipal Wastewater Treatment Facility.

\begin{tabular}{cc}
\hline Parameter & Value \\
\hline Temperature & $25.8^{\circ} \mathrm{C}$ \\
pH & 7.24 \\
Salinity & 0.5 \\
Conductivity & $913 \mathrm{\mu s} \mathrm{cm}^{-1}$ \\
Total solid (TS) & $0.013 \mathrm{~g} \mathrm{~L}^{-1}$ \\
Total dissolved solid (TDS) & $45.9 \mathrm{mg} \mathrm{L}^{-1}$ \\
Turbidity & $67.8 \mathrm{NTU}^{-1}$ \\
Chemical oxygen demand (COD) & $12.4 \mathrm{mg} \mathrm{L}^{-1}$ \\
Total nitrogen (TN) & $30.9 \mathrm{mg} \mathrm{L}^{-1}$ \\
Ammonia (NH $\left.\mathrm{N}_{3}-\mathrm{N}\right)$ & $29.19 \mathrm{mg} \mathrm{L}^{-1}$ \\
Nitrate $\left(\mathrm{NO}_{3}-\mathrm{N}\right)$ & $\mathrm{N.D.}^{1}$ \\
Total phosphorus (TP) & $2.29 \mathrm{mg} \mathrm{L}^{-1}$ \\
\hline Element concentration & $\left(\mathrm{mg} \mathrm{L}^{-1}\right)$ \\
$\mathrm{Na}$ & 64.28 \\
$\mathrm{Ca}$ & 50.09 \\
$\mathrm{~K}$ & 13.74 \\
$\mathrm{Fe}$ & 0.69 \\
$\mathrm{Mg}$ & 10.32 \\
$\mathrm{P}$ & 2.39 \\
$\mathrm{~S}$ & 28.93 \\
\hline
\end{tabular}

${ }^{1} \overline{\text { Not detected (below 0.1-mg L }}{ }^{-1}$ detection threshold). 


\subsection{Measurement of Growth Rate and Biomass Productivity}

In growth and biomass analyses, Desmodesmus sp. KNUA024 was the most productive species, showing significantly higher OD, cell count, and dry weight at each time point (Figure 2). The specific growth rates, which were calculated using cell counting, were $6.93 \pm 0.02 \mathrm{~d}^{-1}$ for Tetradesmus obliquus KNUA019, $6.20 \pm 0.17 \mathrm{~d}^{-1}$ for Asterarcys quadricellulare KNUA020, $7.34 \pm 0.08 \mathrm{~d}^{-1}$ for Desmodesmus sp. KNUA024, and $5.39 \pm 0.06 \mathrm{~d}^{-1}$ for Pseudopediastrum sp. KNUA039. Furthermore, the rapid increase in $\mathrm{pH}$ early in the culture period, a trend suggestive of growth, also indicates that Desmodesmus sp. KNUA024 was the fastest growing. Tetradesmus obliquus KNUA019 and A. quadricellulare KNUA020 showed similar growth patterns when all measurements of growth were considered collectively, and Pseudopediastrum sp. KNUA039 grew the most slowly. Consistent with its rapid growth, Desmodesmus sp. KNUA024 was the most productive, but T. obliquus KNUA019, A. quadricellulare KNUA020, and Pseudopediastrum sp. KNUA039 were similar in biomass to Desmodesmus sp. KNUA024.

(a)



(c)

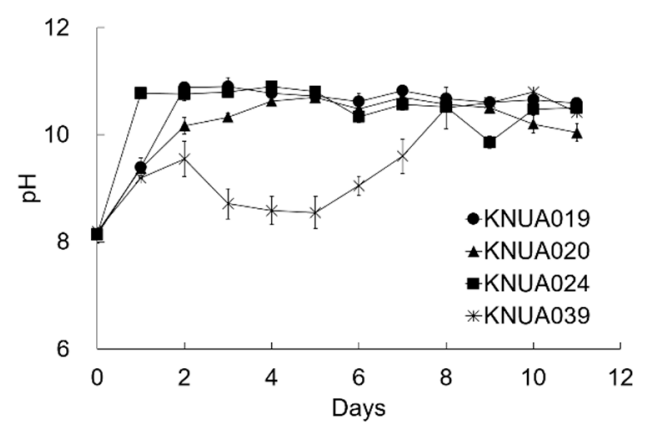

(b)

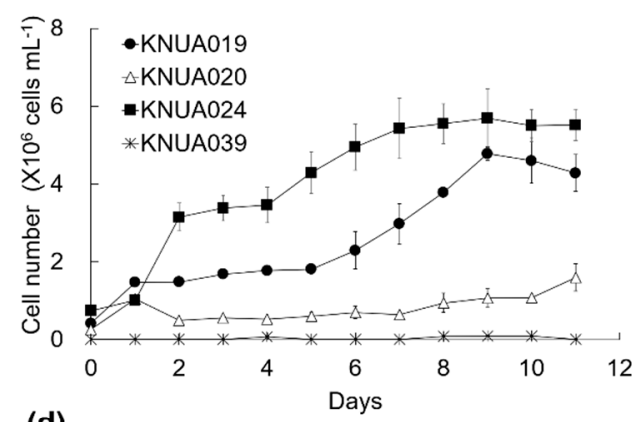

(d)

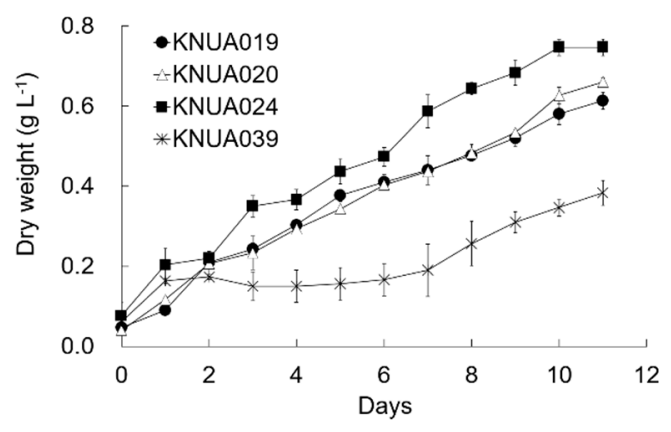

Figure 2. Growth parameters of (a) optical density, (b) cell number, (c) pH, and (d) dry weight of candidate microalgal strain in treated, primary settled wastewater.

\subsection{Nutrient Removal Efficiency}

$\mathrm{TN}, \mathrm{TP}$ and ammonia $\left(\mathrm{NH}_{3}-\mathrm{N}\right)$ concentration decreased in all strains (Figure 3). However, only Desmodesmus sp. KNUA024 attained over 90\% removal of all of three nutrients. Species varied in removal rate of individual nutrients. Desmodesmus sp. KNUA024 removed TP in 6 days, but Pseudopediastrum sp. KNUA039 needed 11 days. All strains showed expeditious consumption of nutrients, except for Pseudopediastrum sp. KNUA039, with exceptional growth in 2 days. Desmodesmus sp. KNUA024 was also expeditious in TP removal, consuming 92.6\% in 1 day. Conversely, Pseudopediastrum sp. KNUA039 removed all nutrients slower than others, and seemed to consume no phosphorus between days 2-6. However, regarding cultivation, it removed $66.31 \%$ of $\mathrm{TN}, 97.84 \%$ of $\mathrm{NH}_{3}-\mathrm{N}$, and $80.43 \%$ of TP. 
(a)

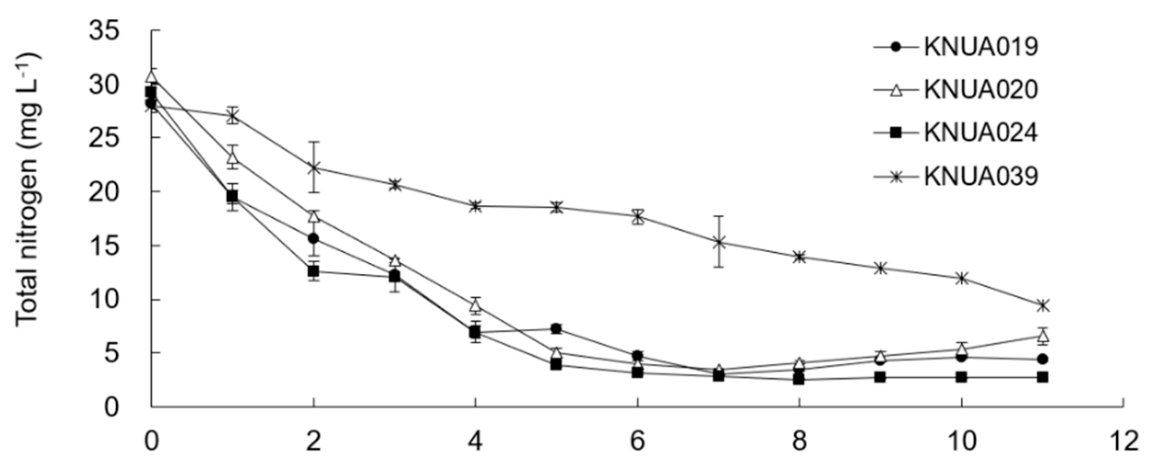

(b)
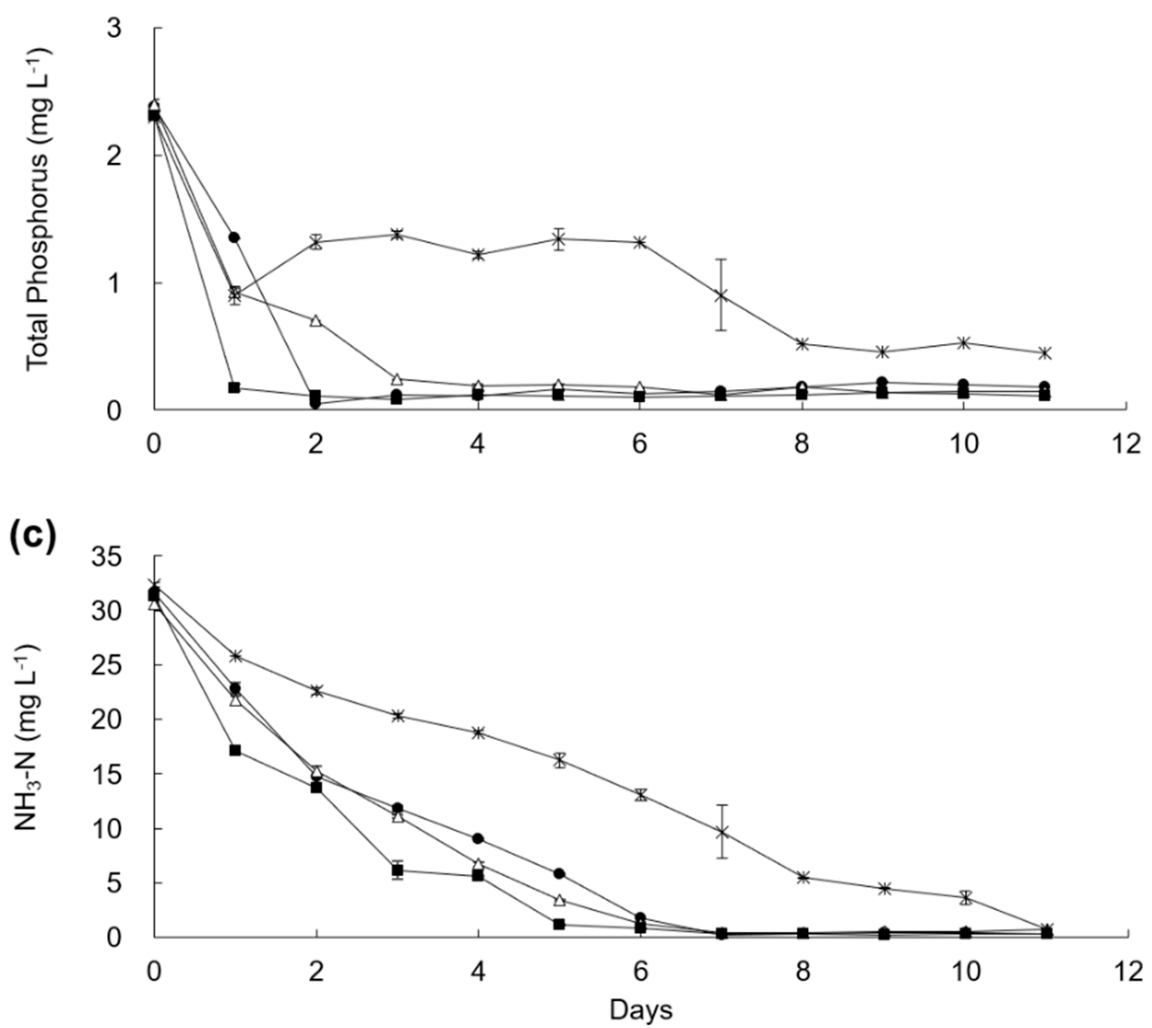

Figure 3. Changes in (a) total nitrogen, (b) total phosphorus, and (c) ammonia concentration for candidate microalgal strains in treated, primary settled wastewater.

\subsection{Chlorophyll and Total Carotenoid Contents}

As with biomass, chlorophylls and total carotenoid contents were measured when each microalgal strain had removed the maximum total nitrogen (Figure 4). Desmodesmus sp. KNUA024 had more chlorophyll $a$, chlorophyll $b$, and total carotenoids than other species, whereas A. quadricellulare KNUA020 had consistently lower values for each, with approximately 7.4 times less chlorophyll $a$ than Desmodesmus sp. KNUA024 and 3.4 times less than Pseudopediastrum sp. KNUA039. 


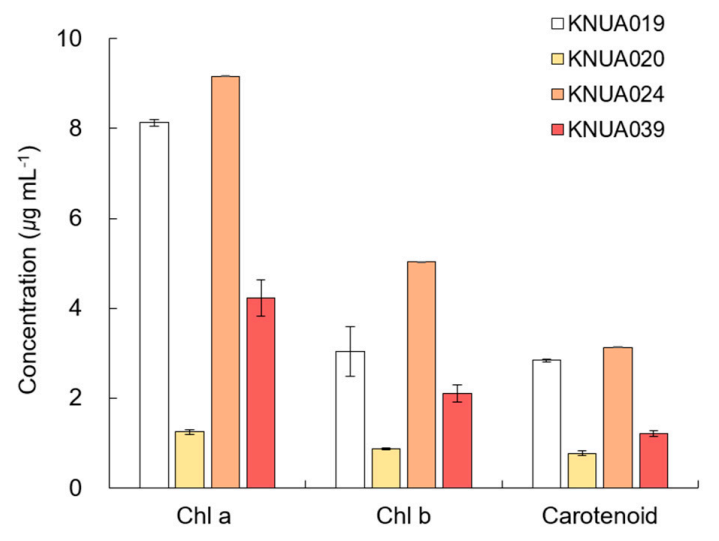

Figure 4. Chlorophyll $a(\mathrm{Chl} \mathrm{a})$, chlorophyll $b(\mathrm{Chl} \mathrm{b})$, and total carotenoid concentrations of microalgal strains after maximum total nitrogen removal in treated, primary settled wastewater.

\subsection{Biochemical Analysis}

Among all strains, total protein was the predominant component (Table 2), particularly in Desmodesmus sp. KNUA024, the weight of which was nearly $40 \%$ protein. Tetradesmus obliquus KNUA019 and A. quadricellulare KNUA020, which showed similar patterns in growth rate and biomass productivity to one another, possessed almost identical carbohydrate and protein contents, but differed substantially in lipid content (22.38\% and $16.99 \%$, respectively). The slowest-growing species, Pseudopediastrum sp. KNUA039, had the highest lipid content, 1.56 times higher than the strain with the lowest lipid content, A. quadricellulare KNUA020.

Table 2. Biochemical composition (percent of total weight) of microalgal biomass in treated, primary settled wastewater.

\begin{tabular}{cccc}
\hline & Carbohydrate & Protein & Lipid \\
\hline Tetradesmus obliquus KNUA019 & $27.24 \pm 2.39$ & $34.29 \pm 0.0$ & $22.38 \pm 3.42$ \\
Asterarcys quadricellulare KNUA020 & $26.98 \pm 1.91$ & $35.78 \pm 0.77$ & $16.99 \pm 2.56$ \\
Desmodesmus sp. KNUA024 & $24.41 \pm 0.99$ & $39.66 \pm 0.18$ & $23.51 \pm 3.62$ \\
Pseudopediastrum sp. KNUA039 & $27.86 \pm 3.49$ & $32.15 \pm 0.13$ & $26.45 \pm 3.28$ \\
\hline
\end{tabular}

\subsection{Proximate and Ultimate Analysis}

Across all microalgal strains, volatile matter was over $88 \%$ and carbon over $41 \%$, with Pseudopediastrum sp. KNUA039 possessing the highest values for both (Table 3). Furthermore, CV, which was calculated from proximate and ultimate analysis, was also the highest in Pseudopediastrum sp. KNUA039, at $20.5 \mathrm{MJ} \mathrm{kg}^{-1}$.

Table 3. Proximate and ultimate analysis of microalgal biomass.

\begin{tabular}{|c|c|c|c|c|}
\hline & $\begin{array}{c}\text { Tetradesmus obliquus } \\
\text { KNUA019 }\end{array}$ & $\begin{array}{c}\text { Asterarcys quadricellulare } \\
\text { KNUA020 }\end{array}$ & $\begin{array}{l}\text { Desmodesmus sp. } \\
\text { KNUA024 }\end{array}$ & $\begin{array}{c}\text { Pseudopediastrum sp. } \\
\text { KNUA039 }\end{array}$ \\
\hline \multicolumn{5}{|c|}{ Proximate analysis (wt $\%$ ) } \\
\hline $\mathrm{MC}^{1}$ & $5.9 \pm 0.0$ & $6.6 \pm 0.2$ & $5.9 \pm 0.3$ & $5.6 \pm 0.1$ \\
\hline $\mathrm{VM}^{2}$ & $90.6 \pm 0.3$ & $88.8 \pm 0.1$ & $88.9 \pm 0.2$ & $91.8 \pm 0.5$ \\
\hline Ash & $3.7 \pm 0.3$ & $4.6 \pm 0.3$ & $5.2 \pm 0.6$ & $2.5 \pm 0.6$ \\
\hline \multicolumn{5}{|c|}{ Ultimate analysis (wt $\%)$} \\
\hline $\mathrm{C}$ & $44.9 \pm 0.4$ & $41.6 \pm 0.9$ & $44.6 \pm 0.8$ & $46.1 \pm 0.2$ \\
\hline $\mathrm{H}$ & $6.7 \pm 0.1$ & $6.6 \pm 0.0$ & $6.6 \pm 0.2$ & $7.1 \pm 0.1$ \\
\hline $\mathrm{O}$ & $38.8 \pm 0.8$ & $40.9 \pm 0.8$ & $36.9 \pm 0.4$ & $38.8 \pm 0.4$ \\
\hline $\mathrm{N}$ & $5.5 \pm 0.0$ & $5.7 \pm 0.1$ & $6.3 \pm 0.0$ & $5.1 \pm 0.0$ \\
\hline$S$ & $0.5 \pm 0.0$ & $0.6 \pm 0.0$ & $0.4 \pm 0.0$ & $0.4 \pm 0.0$ \\
\hline $\mathrm{CV}^{3}\left(\mathrm{MJ} \mathrm{kg}^{-1}\right)$ & $19.5 \pm 0.4$ & $18.0 \pm 0.4$ & $19.5 \pm 0.2$ & $20.5 \pm 0$ \\
\hline
\end{tabular}

${ }^{1}$ Moisture content; ${ }^{2}$ Volatile matter; ${ }^{3}$ Calorific value [20]. 


\subsection{FAME Analysis with GC/MS}

Analysis of the fatty acid composition of entire microalgal biomasses revealed predominantly palmitic acid, oleic acid, and $\alpha$-linolenic acid (Figure 5). Among these results, the polyunsaturated fatty acid (PUFA) $\alpha$-linolenic acid was most abundant in Desmodesmus sp. KNUA024. In contrast, monounsaturated fatty acid (MUFA) content was lowest in Desmodesmus sp. KNUA024 (22.76\%) and highest in Pseudopediastrum sp. KNUA039 (41.36\%, 38.77\% of which was oleic acid). Tetradesmus obliquus KNUA019 and A. quadricellulare KNUA020 had similar fatty acid results.



Figure 5. Fatty acid methyl-ester composition of the microalgal biomass in treated, primary settled wastewater.

\subsection{Biodiesel and Bio-Lubricant Properties Based on FAME Profiles}

Several factors describe biofuel properties, including CN, CFPP, and oxidation stability (OS). With a CN of 55.3, only Pseudopediastrum sp. KNUA039 exceeded the EN14214 standard of a CN greater than 51 (Table 4). Conversely, Desmodesmus sp. KNUA024 had the highest iodine values, due to its high PUFA content.

Table 4. Biodiesel properties of microalgal biomass in treated, primary settled wastewater, calculated by fatty acid methyl-ester composition.

\begin{tabular}{ccccc}
\hline & $\begin{array}{c}\text { Tetradesmus obliquus } \\
\text { KNUA019 }\end{array}$ & $\begin{array}{c}\text { Asterarcys quadricellulare } \\
\text { KNUA020 }\end{array}$ & $\begin{array}{c}\text { Desmodesmus sp. } \\
\text { KNUA024 }\end{array}$ & $\begin{array}{c}\text { Pseudopediastrum sp. } \\
\text { KNUA039 }\end{array}$ \\
\hline SV & 183 & 179 & 181 & 170 \\
IV & 150 & 131 & 170 & 95 \\
CN & 41.0 & 44.7 & 34.6 & 55.3 \\
DU & 114 & 102 & 122 & 91 \\
LCSF & 2.8 & 3.0 & 2.0 & 2.2 \\
CFPP & -7.7 & -7.0 & -10.1 & -9.7 \\
OS & 6.4 & 6.8 & 5.9 & 8 \\
$v$ & 3.64 & 3.76 & 3.39 & 3.92 \\
$\varrho$ & 0.89 & 0.88 & 0.89 & 0.83 \\
\hline
\end{tabular}

SV: Saponification Value; IV: Iodine Value $\left(\mathrm{g} \mathrm{I}_{2} 100 \mathrm{~g}^{-1}\right.$ fat); CN: Cetane Number; DU: Degree of Unsaturation; LCSF: Long-Chain Saturated Factor; CFPP: Cold Filter Plugging Point $\left({ }^{\circ} \mathrm{C}\right)$; OS: Oxidation Stability (h); v: Kinematic Viscosity $\left(\mathrm{mm}^{2} \mathrm{~s}^{-1}\right)$; $\varrho$ : Density $\left(\mathrm{g} \mathrm{cm}^{-3}\right)$.

\section{Discussion}

After screening 22 candidate microalgal strains in artificial wastewater, T. obliquus KNUA019 and A. quadricellulare KNUA020 were proved to be the most tolerant of changing medium conditions, including $\mathrm{pH}$ decrease, and grew healthily for longer than other strains. Because of these characteristics, both were selected from the viability trials as candidates for actual wastewater treatment. A difficulty in maintaining a microalgal monoculture in mass cultivation is the combination of seasonal weather 
changes and predators, which threaten growth conditions and strain transitions, respectively. Desmodesmus sp. KNUA024 and Pseudopediastrum sp. KNUA039, isolated from Chilgok mass cultivation, overcame these difficulties and dominated the open pond raceway system throughout the year. Given their tolerance of these conditions and resilience of natural stressors, these two strains also became promising candidates.

Among these four candidates, Desmodesmus sp. KNUA024 had the highest growth rate and biomass productivity, and concomitantly efficient removal of $\mathrm{NH}_{3}-\mathrm{N}, \mathrm{TN}$, and $\mathrm{TP}$, removing $92.6 \%$ of TP in one day. At the conclusion of this study, the wastewater treated by Desmodesmus sp. KNUA024 cultivation met Korean effluent water quality standards. Conversely, Pseudopediastrum sp. KNUA039 had the slowest growth rate as assessed by cell number, but relatively high productivity, due to its large cell size. Due to its slow growth, TN removal by Pseudopediastrum sp. KNUA039 was also the slowest of the four strains evaluated, and its dead cells were more frequently observed than those of other strains. Its low nutrient removal efficiency and $\mathrm{pH}$ increase in culture could indicate that it requires an adaptation period in wastewater. Across all strains, TN increased after microalgae reached the maximum nitrogen removal point because, at this point, dying cells increase and their components degrade, contributing to total nitrogen concentration. Although removal of TN and TP does not represent all the possibilities and efficiencies of wastewater treatment, these results may provide important fundamental data for the next step in treating wastewater, using the characterized microalgae.

In most biochemical analyses of microalgae, the protein content of the biomass is high. In this study, protein content exceeded carbohydrate and lipid content in all four strains. These findings suggest the potential of microalgae as a source of protein and carbohydrates for livestock feed, the commercialization of which is currently under study [26]. Therefore, the approach that we explored in this study has potential use for animal feedstock or bio-fertilizer applications.

In proximate analysis by TGA, all candidate microalgae after wastewater treatment had relatively low moisture content (5.5-6.1\%) and high volatile matter (88.8-91.5\%), indicating their combustion efficiency. These results suggest the suitability of the strains used in this study for biofuel applications, because they have an appropriate moisture content $(<10 \%)$ [19] and higher volatile matter content than conventional sources of bioenergy generation content (crop: $63-80 \%$, wood: 72-78\%) [27]. Furthermore, the $\mathrm{CV}$ of microalgae used here rivaled that of terrestrial energy crops $\left(17-20 \mathrm{MJ} \mathrm{kg}^{-1}\right)$ [28]. Overall, the high photosynthetic efficiency, biomass productivity, and nutrient removal rate, coupled with the bioenergetic availability of microalgae strains used here, indicate the potential use of microalgae as an alternative wastewater treatment system and biomass feedstock, superior to that of crop plants.

The most common fatty acids found in manufactured biodiesel are palmitic acid, stearic acid, oleic acid, linoleic acid, and linolenic acid [29]. Free fatty acids generally comprise only $1-2 \%$ of the lipids in microalgae; most fatty acids are incorporated into triacylglycerols. Among these, only triglycerides are easily converted into biodiesel by transesterification [30]. Our FAME analyses indicated that PUFA are the major fatty acid components in the microalgal strains used here, except for Pseudopediastrum sp. KNUA039, which possessed more MUFA than PUFA. Although most of the microalgal FAME results complied with ASTM 6751 and EN 14214 standards for biodiesel (e.g., DU, LCSF and CFPP), only Pseudopediastrum sp. KNUA039 met the requisite $\mathrm{CN}$ value because of its high SFA and MUFA content. Due to high PUFA contents, other strains have relatively lower SV and IV, which, in turn, results in a lower $\mathrm{CN}$ value.

Bio-lubricants can be produced by modifying fatty acid chemical structures. Utility is positively related to IV value, because the calculated IV value from FAME contents indicates the DU in the biomass. According to a vegetable oil study, oils can be classified as drying (IV > 130), semi-drying $(100<$ IV < 130), or non-drying (IV < 100) [31]. Furthermore, the more unsaturated the fatty acid, the more receptive it is to chemical modification for use as a bio-lubricant. In our study, the highest IV value was in Desmodesmus sp. KNUA024, which scored 170, indicating that it has the best potential for use as a bio-lubricant. 
In this study, we observed effective wastewater treatment by Desmodesmus sp. KNUA024, which is adapted to variable Korean weather conditions. Desmodesmus sp. also shows promise as a suitable microalgal strain for wastewater treatment in Mexico, China, and Brazil [32-34]. Furthermore, the remaining biomass had potential use as bio-lubricant and bioenergy, according to its FAME content and CV. However, more research about the adequate scaling of Desmodesmus sp. KNUA 024 in a monoculture is necessary before replacing conventional wastewater treatment systems. However, given the dominance of Desmodesmus sp. KNUA024 in mass cultivation of an open pond raceway system in Korea, we are optimistic about its potential. Our findings provide a basic step for the identification of microalgal strains appropriate for local conditions, and further studies should explore its practical applications for larger scale wastewater treatments.

Supplementary Materials: The following are available online at http://www.mdpi.com/2073-4441/11/11/2294/s1. Figure S1: Screening of 20 KNUA microalgal strains on artificial wastewater agar medium. Table S1: Total nitrogen, ammonia, and total phosphorus removal rate of microalgal strains. The word in the parenthesis indicates the days which each strain achieved the maximum total nitrogen removal. Table S2: Fatty acid profile of microalgal biomass in treated primary settled wastewater.

Author Contributions: J.-M.D. was involved in the conceptualization, laboratory work, data analysis, drafting, and editing of the manuscript; S.-W.J. was involved in the conceptualization, experimental design, and data curation; I.-S.K. was involved in conceptualization; H.N. was involved in laboratory work; J.H.L. was involved in laboratory work; H.S.K. was involved in laboratory work; H.-S.Y. was involved in the conceptualization and editing of the manuscript.

Funding: This research was supported by a grant from the National Research Foundation of Korea (2017R1A2B4002016).

Conflicts of Interest: The authors declare no conflict of interest.

\section{References}

1. Zhu, B.; Chen, G.; Cao, X.; Wei, D. Molecular Characterization of $\mathrm{CO}_{2}$ Sequestration and Assimilation in Microalgae and Its Biotechnological Applications. Bioresour. Technol. 2017, 5, 199. [CrossRef] [PubMed]

2. Bozbas, K. Biodiesel as an Alternative Motor Fuel: Production and Policies in the European Union. Renew. Sustain. Energy Rev. 2008, 12, 542-552. [CrossRef]

3. Mondal, M.; Goswami, S.; Ghosh, A.; Oinam, G.; Tiwari, O.N.; Das, P.; Gayen, K.; Mandal, M.K.; Halder, G.N. Production of Biodiesel from Microalgae through Biological Carbon Capture: A Review. 3 Biotech. 2017, 7, 1-21. [CrossRef] [PubMed]

4. Slade, R.; Bauen, A. Micro-Algae Cultivation for Biofuels: Cost, Energy Balance, Environmental Impacts and Future Prospects. Biomass Bioenergy 2013, 53, 29-38. [CrossRef]

5. Ji, M.K.; Abou-Shanab, R.A.I.; Kim, S.H.; Salama, E.S.; Lee, S.H.; Kabra, A.N.; Lee, Y.S.; Hong, S.; Jeon, B.H. Cultivation of Microalgae Species in Tertiary Municipal Wastewater Supplemented with $\mathrm{CO}_{2}$ for Nutrient Removal and Biomass Production. Ecol. Eng. 2013, 58, 142-148. [CrossRef]

6. Cheng, D.L.; Ngo, H.H.; Guo, W.S.; Chang, S.W.; Nguyen, D.D.; Kumar, S.M. Microalgae Biomass from Swine Wastewater and Its Conversion to Bioenergy. Bioresour. Technol. 2019, 275, 109-122. [CrossRef]

7. Abou-Shanab, R.A.I.; Ji, M.-K.; Kim, H.-C.; Paeng, K.-J.; Jeon, B.-H. Microalgal Species Growing on Piggery Wastewater as a Valuable Candidate for Nutrient Removal and Biodiesel Production. J. Environ. Manag. 2013, 115, 257-264. [CrossRef]

8. Wu, L.F.; Chen, P.C.; Huang, A.P.; Lee, C.M. The Feasibility of Biodiesel Production by Microalgae Using Industrial Wastewater. Bioresour. Technol. 2012, 113, 14-18. [CrossRef]

9. Sebastian, S.; Nair, K.V.K. Total Removal of Coliforms and E. Coli from Domestic Sewage by High-Rate Pond Mass Culture of Scenedesmus Obliquus. Environ. Pollut. Ser. A Ecol. Biol. 1984, 34, 197-206. [CrossRef]

10. Stemmler, K.; Massimi, R.; Kirkwood, A.E. Growth and Fatty Acid Characterization of Microalgae Isolated from Municipal Waste-Treatment Systems and the Potential Role of Algal-Associated Bacteria in Feedstock Production. PeerJ. 2016, 4, e1780. [CrossRef]

11. Feng, Y.; Li, C.; Zhang, D. Lipid Production of Chlorella Vulgaris Cultured in Artificial Wastewater Medium. Bioresour. Technol. 2011, 102, 101-105. [CrossRef] [PubMed]

12. Stanier, R.Y.; Deruelles, J.; Rippka, R.; Herdman, M.; Waterbury, J.B. Generic Assignments, Strain Histories and Properties of Pure Cultures of Cyanobacteria. Microbiol. 1979, 111, 1-61. [CrossRef] 
13. Hong, J.W.; Kim, O.H.; Jo, S.W.; Do, J.M.; Yoon, H.S. Microalgal Biomass Productivity and Dominant Species Transition in a Korean Mass Cultivation System. Algal Res. 2017, 26, 365-370. [CrossRef]

14. Rice, E.W. Standard Methods for the Examination of Water and Wastewater, 22nd ed.; American Water Works Association: Washington, DC, USA, 2012.

15. Levasseur, M.; Thompson, P.A.; Harrison, P.J. Physiological Acclimation of Marine Phytoplankton to Different Nitrogen Sources. J. Phycol. 1993, 29, 587-595. [CrossRef]

16. Wellburn, A.R. The Spectral Determination of Chlorophylls $a$ and $b$, as Well as Total Carotenoids, Using Various Solvents with Spectrophotometers of Different Resolution. J. Plant Physiol. 1994, 144, 307-313. [CrossRef]

17. Mariotti, F.; Tomé, D.; Mirand, P.P. Converting Nitrogen into Protein-Beyond 6.25 and Jones' Factors. Crit. Rev. Food Sci. Nutr. 2008, 48, 177-184. [CrossRef] [PubMed]

18. Mishra, S.K.; Suh, W.I.; Farooq, W.; Moon, M.; Shrivastav, A.; Park, M.S.; Yang, J.W. Rapid Quantification of Microalgal Lipids in Aqueous Medium by a Simple Colorimetric Method. Bioresour. Technol. 2014, 155, 330-333. [CrossRef]

19. Bi, Z.; He, B.B. Characterization of Microalgae for the Purpose of Biofuel Production. Trans. ASABE 2013, 56, 1529-1539. [CrossRef]

20. Given, P.H.; Weldon, D.; Zoeller, J.H. Calculation of Calorific Values of Coals from Ultimate Analyses: Theoretical Basis and Geochemical Implications. Fuel 1986, 65, 849-854. [CrossRef]

21. Breuer, G.; Evers, W.A.C.; de Vree, J.H.; Kleinegris, D.M.M.; Martens, D.E.; Wijffels, R.H.; Lamers, P.P. Analysis of Fatty Acid Content and Composition in Microalgae. J. Vis. Exp. 2013, 80, e50628. [CrossRef]

22. Ramos, M.J.; Fernández, C.M.; Casas, A.; Rodríguez, L.; Pérez, Á. Influence of Fatty Acid Composition of Raw Materials on Biodiesel Properties. Bioresour. Technol. 2009, 100, 261-268. [CrossRef] [PubMed]

23. Francisco, É.C.; Neves, D.B.; Jacob-Lopes, E.; Franco, T.T. Microalgae as Feedstock for Biodiesel Production: Carbon Dioxide Sequestration, Lipid Production and Biofuel Quality. J. Chem. Technol. Biotechnol. 2010, 85, 395-403. [CrossRef]

24. Islam, M.A.; Magnusson, M.; Brown, R.J.; Ayoko, G.A.; Nabi, M.N.; Heimann, K. Microalgal Species Selection for Biodiesel Production Based on Fuel Properties Derived from Fatty Acid Profiles. Energies 2013, 6, 5676-5702. [CrossRef]

25. Wu, H.; Miao, X. Biodiesel Quality and Biochemical Changes of Microalgae Chlorella Pyrenoidosa and Scenedesmus Obliquus in Response to Nitrate Levels. Bioresour. Technol. 2014, 170, 421-427. [CrossRef]

26. Caporgno, M.P.; Mathys, A. Trends in Microalgae Incorporation into Innovative Food Products with Potential Health Benefits. Front. Nutr. 2018, 5, 58. [CrossRef]

27. Hong, J.W.; Kim, O.H.; Jo, S.-W.; Kim, H.; Jeong, M.R.; Park, K.M.; Lee, K.I.; Yoon, H.-S. Biochemical Composition of a Korean Domestic Microalga Chlorella Vulgaris KNUA027. Microbiol. Biotechnol. Lett. 2016, 44, 400-407. [CrossRef]

28. Ross, A.B.; Jones, J.M.; Kubacki, M.L.; Bridgeman, T. Classification of Macroalgae as Fuel and Its Thermochemical Behaviour. Bioresour. Technol. 2008, 99, 6494-6504. [CrossRef]

29. Knothe, G. "Designer" Biodiesel: Optimizing Fatty Ester Composition to Improve Fuel Properties. Energy Fuels 2008, 22, 1358-1364. [CrossRef]

30. Nascimento, I.A.; Marques, S.S.I.; Cabanelas, I.T.D.; Pereira, S.A.; Druzian, J.I.; de Souza, C.O.; Vich, D.V.; de Carvalho, G.C.; Nascimento, M.A. Screening Microalgae Strains for Biodiesel Production: Lipid Productivity and Estimation of Fuel Quality Based on Fatty Acids Profiles as Selective Criteria. Bioenergy Res. 2013, 6, 1-13. [CrossRef]

31. Karmakar, G.; Ghosh, P.; Sharma, B. Chemically Modifying Vegetable Oils to Prepare Green Lubricants. Lubricants 2017, 5, 44. [CrossRef]

32. Komolafe, O.; Velasquez Orta, S.B.; Monje-Ramirez, I.; Noguez, I.Y.; Harvey, A.P.; Orta Ledesma, M.T. Biodiesel Production from Indigenous Microalgae Grown in Wastewater. Bioresour. Technol. 2014, 154, 297-304. [CrossRef] [PubMed] 
33. Ji, F.; Liu, Y.; Hao, R.; Li, G.; Zhou, Y.; Dong, R. Biomass Production and Nutrients Removal by a New Microalgae Strain Desmodesmus sp. in Anaerobic Digestion Wastewater. Bioresour. Technol. 2014, 161, $200-207$. [CrossRef] [PubMed]

34. Santiago, A.F.; Calijuri, M.L.; Assemany, P.P.; Calijuri, M.D.C.; Dos Reis, A.J.D. Algal Biomass Production and Wastewater Treatment in High Rate Algal Ponds Receiving Disinfected Effluent. Environ. Technol. 2013, 34, 1877-1885. [CrossRef] [PubMed] 